\title{
Smart assessment of thermal comfort concept inside a building
}

\author{
Chihebedine Beji ${ }^{1, *}$, Sami Bouzaiane ${ }^{2}$, and Nahla Bouaziz ${ }^{1}$ \\ ${ }^{1}$ Université de Tunis El Manar, Ecole nationale d'Ingénieur de Tunis, unité de recherche énergétique et environnement, BP 37 le \\ belvédère, 1002 Tunis, Tunisia. \\ ${ }^{2}$ Académie Navale, Menzel Bourguiba, 7050, Bizerte, Tunisia
}

\begin{abstract}
The growing energy consumption of the building sector is becoming a current issue affecting both environmental and economical fields. The present paper investigates thermal comfort conditions inside the manuscript room of the National library of Tunisia by using an IoT based smart measuring system. The tracked parameters are temperature and relative humidity. These parameters are considered as the fundamental factors influencing thermal comfort inside a building. The results of this survey performed during the month of January 2019 lead us to propose an energy optimization measure, in order to update heating system electricity consumption. The proposed approach consists of the use of phase change materials (PCM) window shutters. PCM window shutters can act as thermal regulators thanks to their melting solidification process. The results of the proposed solution showed that adopting PCM window shutters for the examined test room can save up to $10 \%$ for the first phase change material and $15 \%$ for the second phase change material of the total energy used by the heat pump unit to maintain the inside air temperature at $21^{\circ} \mathrm{C}$.
\end{abstract}

\section{Introduction}

In recent years, energy consumption growth of the building sector has become an issue concerning both developed and less developed countries. In fact, according to the IEA, the buildings in general and buildings construction sectors, in particular, are responsible for $36 \%$ of global final energy consumption and nearly $40 \%$ of the total direct and indirect $\mathrm{CO} 2$ emissions. Hence, optimizing the building sector energy consumption by enhancing its efficiency has become an essential priority to reach IEA 2050 plan aiming at reducing carbon emissions by $77 \%$.

On the national scale, Tunisia has witnessed an increase in residential buildings number from 1 million in 1975 to more than 2.7 million in 2007[1]. Furthermore, the increase of buildings energy consumption in Tunisia is due to the upgrade of the living standards among Tunisians, resulted in an increase of energy used for heating and cooling from $20 \%$ in 1989 to $26 \%$ in 2004 [2]. It is obvious that the increasing consumption of the building sector will affect multiple aspects and imposes new challenges.

First, the major part of the energy used by the building is coming from fossil sources. This high dependency on such sources has a direct effect on raising the amount of $\mathrm{CO} 2$ emissions in the atmosphere, and thus increasing the risks and intensity of global warming. Secondly, higher energy consumption will provoke more spending on extracting energy from fossil sources to meet the growing demand. For instance, in the case of Tunisia, the energy used for housing units has expanded from 0.3 $\mathrm{TOE} /$ unit in 1990 to $0.41 \mathrm{TOE} / \mathrm{unit}$ in 2006 [2].
Considering several factors such as the constant rise of the petrol barrel price during recent years, the turbulence of the oil market along with the rising energy demand, it is evident that Tunisia's national economy will face stronger challenges.

To work around this expanding issue, researchers aiming at decreasing buildings' energy consumption have explored several techniques. In their article, Ihm and Krarti [2] investigated combining multiple energy efficiency measures, such as building orientation, windows size, air leakage level, and cooling system COP, in order to optimize the design of Tunisian residential villas by applying a sequential search technique. It was found that $49.6 \%$ and $58.8 \%$ of energy could be saved when respectively a set of eight EEM and 9 EEM is selected.

Thermal insulation for buildings walls and roofs has been a well-known procedure to optimize the efficiency of buildings energy consumption by reducing the amount of heat flux through the building envelope. Daouas [3] investigated the optimum thickness of the insulation layer in the case of a typical Tunisian wall in order to decrease the transmission loads through the building envelope. Her work was based on the fact that Tunisia Mediterranean mild climate requires both heating in winter and cooling in summer to reach comfort conditions.

The life cycle cost analysis showed that the south-facing wall is the most economical for an insulation layer of $10.1 \mathrm{~cm}$ of expanded polystyrene, resulting in $71.33 \%$ of energy savings for a payback period of 3.29 years. The aim of all building energy optimization measures investigated by researchers is the reduction of the overall

\footnotetext{
"Chihebedine Beji: chiheb.beji@enit.utm.tn
} 
energy consumption while maintaining acceptable thermal comfort conditions for the occupants. The latter concept is essential for buildings occupants since it is considered slightly important than acoustic comfort and satisfaction with air quality and highly important than visual comfort [4].

In the case of commercial buildings, thermal comfort conditions are usually maintained by heating, ventilation, and air conditioning systems. In fact, HVAC systems account for up to $60 \%$ of the total energy consumption [5]. Therefore, this high dependency on HVAC systems to maintain thermal comfort conditions inside a building is a basic cause of increasing buildings' energy consumption and thus elevating green gashouse emissions in the atmosphere. Hence, minimizing the reliance on such systems in order to maintain optimal thermal comfort conditions will directly reduce commercial building electricity consumption.

As most of the examined approaches studied in the literature investigate several techniques to enhance a building energy performance during the construction phase, optimizing the energy efficiency of an existing building remains a quite difficult task. In this paper, we assessed thermal comfort conditions inside the manuscript room of the National Library of Tunisia, located at $36^{\circ} 48^{\prime} 00^{\prime \prime}$ north, $10^{\circ} 09^{\prime} 50^{\prime \prime}$ East in Tunis city. The results of our survey lead us to propose an optimization measure in order to enhance the energy efficiency of the examined room by reducing the heating system usage while keeping inside thermal comfort conditions at an acceptable range.

\section{Analysis and modelling}

It is expected that the number of online capable devices will reach 30 billion objects by 2020 [6]. As a result, the Internet of Things (IoT) limitless appliances will be engaged in several fields. Moreover, the building sector is an essential market for this technology, since IoT could help us where the power consumption is more and there is a need to save power since everything is monitored on a minute by minute basis in the data room [7].

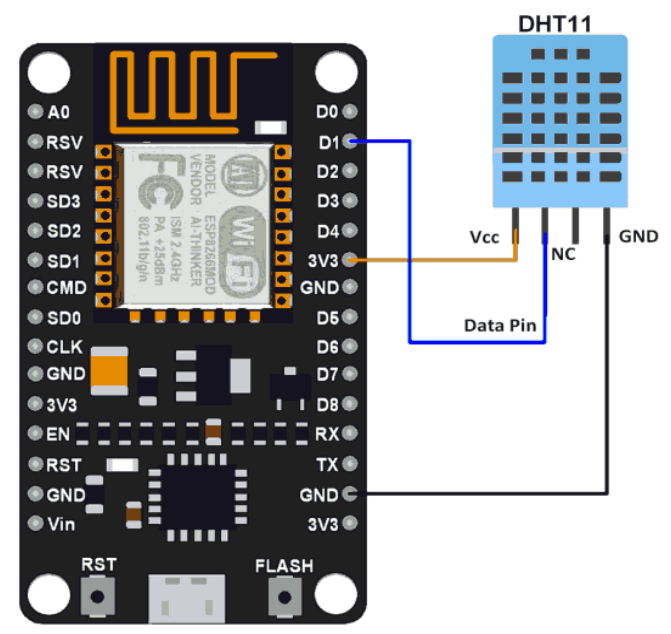

Fig. 1. IoT based monitoring device
In this paper, we adopted an IoT based system presented in Figure 1 to measure air temperature and relative humidity inside the test room. The gathering data task is performed through an IoT model consisting of a Nodemcu board [8] based on ESP8266 microcontroller [9] and the DHT11 air temperature and relative humidity sensor [10]. The measurements data taken by the hardware are transmitted to a smartphone user interface application through an internet cloud service called Blynk. This device makes it possible, among other things, to consult remotely and in real-time the measurements made [11].

The inside temperature was almost kept at $21^{\circ} \mathrm{C}$ and the relative humidity fixed at $15 \%$ due to the temperature control of the heating system for straight 10 hours from 8 am until $6 \mathrm{pm}$. The thermal mass of a building strongly affects the HVAC equipment energy consumption. In this regard, PCMs have been an attractive field of study for scholars aiming at optimizing buildings' energy efficiency. In fact, by incorporating such materials into buildings lightweight envelopes, thermal inertial of the building envelope could significantly improve while providing a natural regulation of internal temperature [12].

A major characteristic of phase change materials is their capability of being used in different building components. Kong et al. [13] experimentally tested PCM panels in order to reduce building energy consumption during summer. Their proposed model consisted of PCM macro encapsulated panels, in which the external sides were field with capric acid (CA) and the interior parts were field with 1-dodecanol (CADE). The results of their study heightened the fact that PCMs are an efficient tool in terms of reducing buildings' energy consumption, and suggested that further studies should investigate the thermal performance of such panels in case of exposing them to constant cooling coming from an air conditioner unit.

In our selected case test room depicted by Revit software in figure [2], there are five major fenestration areas. This large glazing area increases thermal losses between the inside and the outside thermal environment due to the low thermal inertia of the glass, and thus more mechanical heating is required. Hence, phase change materials dynamic thermal characteristics could become an efficient solution in terms of improving windows thermal inertia. Both numerical and experimental studies were conducted in order to assess the impact of combining PCMs with glazing areas on a building energy performance. For instance, a numerical model was developed by Manz et al. [14] to assess the radiative heat transfer through a porotype external wall designed for solar heating set by a transparent insulation material and a translucent phase change material.

The results of their work promoted the thermal optical behavior of the studied wall and suggested lowering the PCM melting temperature from $26.5^{\circ} \mathrm{C}$ to $21^{\circ} \mathrm{C}$ to get the best results in terms of decreasing energy losses through the façade. Goia et al. [15] conducted an experimental study of a prototype PCM glazing system to assess its effect on thermal comfort conditions. They proposed a simple model of PCM glazing unit and 
compared its thermal behavior to a standard double glazed window.

The results of their study showed that the proposed prototype system improved thermal comfort conditions during different seasons, but special attention should be considered when selecting PCM's melting temperature. Duraković and Mešetović [16] experimentally compared the thermal performance of PCM and water-filled glazing systems to a typical glazing unit during summer and winter seasons. The results of their work indicated that the type of the encapsulated material strongly affects the temperature variation of the interior glass surface during a 48 hours survey, while the PCM glazing system was statistically evaluated as the optimal choice due to the variation of its temperature for 3 hours during melting and 4 hours during the solidification process. In our case, the two organic phase change materials RT15 and RT18 manufactured by the German company Rubitherm ${ }^{\circledR}$ were selected to assess their contribution in reducing the energy consumption of the heat pump used to heat the manuscript room at the national library of Tunisia.

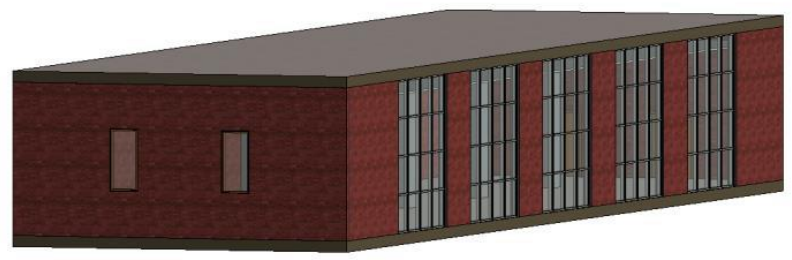

Fig. 2. The manuscript room at the National library of Tunisia

Table 1 summarizes the physical properties of the tested PCMs. The examined structure is located at the first store of the National Library of Tunisia. Its dimensions are $45 \mathrm{~m}$ long, $12 \mathrm{~m}$ wide, and $4.5 \mathrm{~m}$ height as shown in figure 2 using the commercial software Revit. The proposed enhancement measure targets the Northeast facing façade, consisting of five major windows of the size of $5 \mathrm{~m}$ by $5 \mathrm{~m}$. The survey of the examined room was conducted during January. In this work, we propose to encapsulate the selected phase change materials inside pure aluminum lightweight containers with a thermal conductivity value of $237 \mathrm{~W} / \mathrm{mK}$ at $20^{\circ} \mathrm{C}$. The dimensions of the windows curtains are $5 \mathrm{~m}$ by $5 \mathrm{~m}$ with 4 cm thickness.

The results of monitoring the measures of inside air temperature showed that the latter parameter stabilizes after three hours at $21^{\circ} \mathrm{C}$, allowing the selected PCM to reach its melting temperature and initiate the phase change process. To determine the amount of energy stored by the phase change materials, the following assumptions are considered:

- The initial temperature of the PCMs is equal to the outside temperature.
- During the operational time of the heating system, the PCM temperature will vary as same as the room temperature variation.

The PCM stored energy will be determined through the following equation:

$$
\begin{aligned}
Q_{P C M}=\rho_{s} \times V \times & C_{p} \times \Delta T_{\text {solid }}+V \times \rho \times L_{f}+\rho_{l} \times V \\
& \times C_{p} \times \Delta T_{\text {liquid }}
\end{aligned}
$$

Table 1: Physical properties of the tested PCMs.

\begin{tabular}{|c|c|c|c|}
\hline Properties & RT15 & RT18 & Unit \\
\hline Meting point & 14 & 18 & $\left({ }^{\circ} \mathrm{C}\right)$ \\
\hline Freezing point & 16 & 17 & $\left({ }^{\circ} \mathrm{C}\right)$ \\
\hline Heat storage capacity $\pm 7,5 \%$ & $1.5510^{3}$ & $260.10^{3}$ & $(\mathrm{~J} / \mathrm{kg})$ \\
\hline Specific heat capacity & 2000 & 2000 & $(\mathrm{~J} / \mathrm{kgK})$ \\
\hline Density solid & 880 & 880 & $\left(\mathrm{Kg} / \mathrm{m}^{3}\right)$ \\
\hline Density liquid & 770 & 770 & $\left(\mathrm{Kg} / \mathrm{m}^{3}\right)$ \\
\hline Thermal conductivity & 0.2 & 0.2 & $(\mathrm{~W} / \mathrm{mK})$ \\
\hline Volume expansion & 12,5 & 12,5 & $\%$ \\
\hline
\end{tabular}

\section{Results and discussions}

Our current study investigated the energetic contribution of phase change materials incorporated into window shutters in terms of reducing the power consumption of the heating system. Our work was initiated by monitoring the internal temperature variation inside the manuscript room located at the national library of Tunisia. The Internet of Things concept was used to ensure this task through a smart measuring device. The results of this survey conducted during January 2019, showed that the heating system used in the room stabilizes Tin at $21^{\circ} \mathrm{C}$ after three hours of constant functioning, regardless of the outside air temperature degree.

Based on the previous facts, we propose an energy optimization measure consisting of applying PCM window curtains. The efficiency of the proposed approach was evaluated by determining the amount of energy that can be reduced when the phase change material used completely melts. Figure 3 depicts the potential heat pump unit reduced energy for the case of the RT18. The fluctuations examined in Figure 3 shows that when the outside temperature reaches lower values, the phase change material store more energy and therefore minimizing the heating system energetic consumption. 


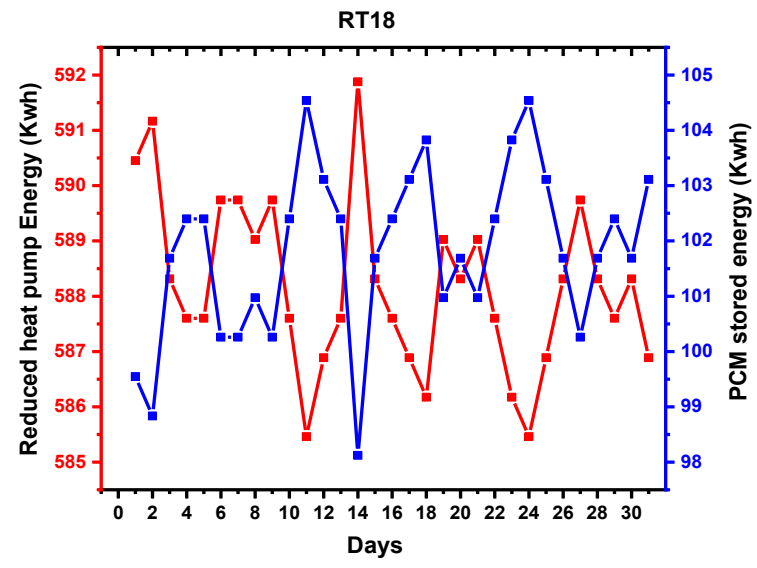

Fig. 3. Reduced heat pump energy during January using PCM material RT 18

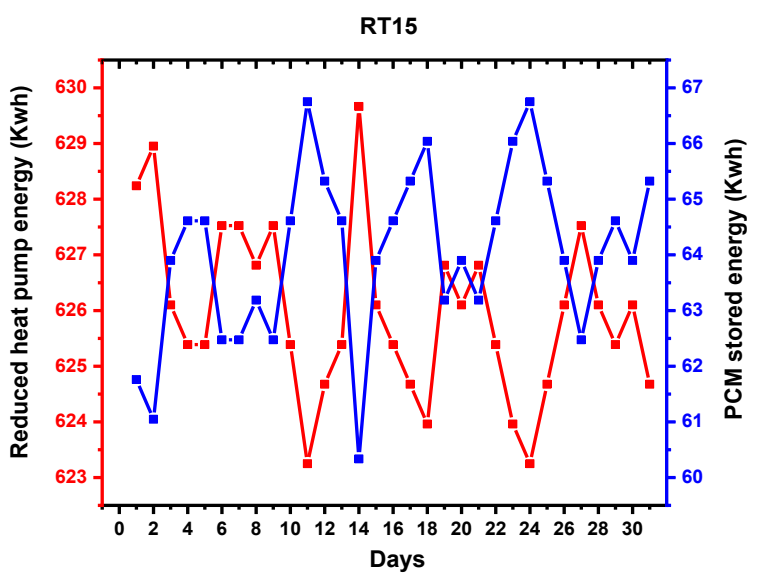

Fig. 4. Reduced heat pump energy during January using PCM material RT 15

The highest energy savings could be obtained on January 11 and January 24, where the RT18 could store an amount of energy of $104.53 \mathrm{Kwh}$, while the lowest energy saving potential is observed in January 14 days when the outside air temperature reached a value of $13^{\circ} \mathrm{C}$. Figure 4 depicts the energy reduced in the case of using RT15as the phase change material. Although the potential saving pattern is identical to the pattern obtained with RT18, the estimated reduction of the heat pump unit was lowered. This regression could be referred to as the fact that RT15 heat of fusion is 59\% inferior to the heat of fusion of the RT18. Figure 5 compares the potential heat pump unit reduced energy for the two evaluated phase change materials.

\section{Conclusion}

Tunisia mild climate requires heating during the winter season to maintain thermal comfort conditions. In the present paper, an energy optimization measure consisting of applying PCM window shutters in the case of the manuscript room located at the National Library of Tunisia was discussed.

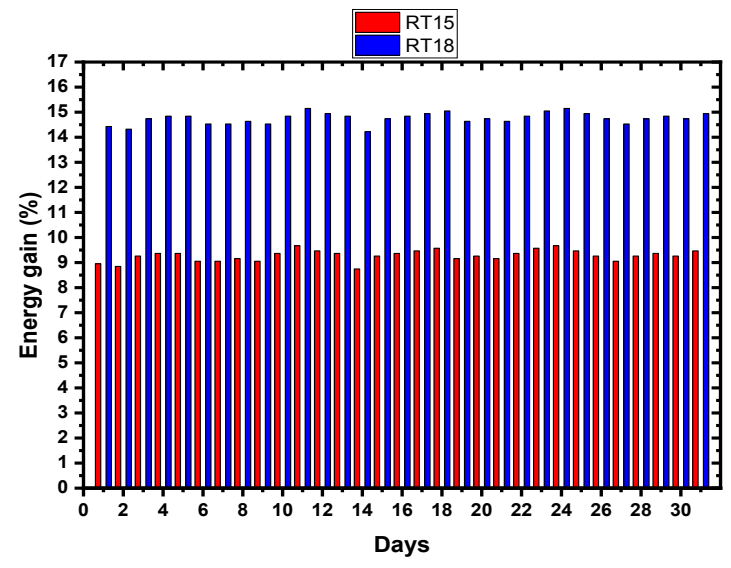

Fig. 5. Potential energy savings using PCMs based curtains

A survey was conducted using a smart IoT system to examine the air temperature variation inside the selected room. Based on the results of our survey, the climatic data provided by the national institute of meteorology and the heating system technical characteristics, the commercial PCMs RT18 and RT15 energy saving potential was estimated. The phase changing process of the latter materials showed promising results in terms of minimizing the energy consumption of the heating system. By selecting RT18, heat pump unit power could be reduced by $15 \%$ and thus electricity consumption will be minimized.

\section{References}

1 UN-HABITAT, "Tunisia Housing Profile", 102, 43, (2011)

2. P. Ihm, M. Krarti, Build Environ, 58, 81, (2012)

3. N. Daouas,Appl. Energy, 177, 136, (2016)

4. M. Frontczak, P. Wargocki, Build Environ, 46, pp, 922-937, (2011)

5. L.Yang, H. Yan, JC. Lam, Appl. Energy, 115, pp, 164-173, (2013)

6. M. Hung, "Leading the IoT, Gartner Insights on How to Lead in a Connected World", pp, 1-29, (2017)

7. S.S. Reka, T. Dragicevic, Renew. Sustain. Energy Rev, 91, 90, (2018).

8. Nodemcu, [Online]. Available: https://www.nodemcu.com/index_en.html/, (2019)

9. ESP8266, [Online]. Available: https://www.espressif.com/sites/default/files/docu mentation/0a-esp8266ex_datasheet_en.pdf, (2019)

10. DHT11. (2019). Available Online: https://learn.adafruit.com/dht?view=all, (2019)

11. Blynk,. Available Online: https://blynk.io/, (2019)

12. A. Madad, F. Mouhib, A. Mouhsen, Buildings, 8(5), 63, (2018)

13. X. Kong, S. Lu, J. Huang, Z. Cai, S. Wei, Energy. Build, 62, 597, (2013) 
14. H. Manz, P. W. Egolf, P. Suter, A. Goetzberger, Sol. Energy, 61, 369 (1997)

15. F.Goia, M.Perino, V.Serra, Energy. Build, 60, 442 (2013)

16. B. Duraković, S. Mešetović, Cities Soc, 45, 422 (2019) 